\title{
Influence of rigidity of the hardened parts on forming the shape accuracy during flat grinding
}

\author{
Yakov I. Soler ${ }^{1}$, Nguyen Van Le ${ }^{1, *}$, and Mai Dinh $\mathrm{Si}^{1}$ \\ ${ }^{1}$ Irkutsk Nation Research Technical University, Department of Technology and Equipment of Machinery Production, 664074, Irkutsk, \\ Russian Federation
}

\begin{abstract}
At present time there is not information about the influence of rigidity of hardened steel parts on the parameters of flatness deviations: $E F E_{\max }, E F E_{a}, E F E_{q}$, which are called correspondingly greatest, arithmetic average and quadratic average. To model the variable rigidity of workpieces, an arrangement with the frame structure was used. It allowed to simulate the variable compliance of parts with constant sizes in the direction of longitudinal feed of grinding machine. Searching for models of multiple dispersion analysis was carried out using the D-optimal plan of experiment. They predicted that in rough grinding all parameters of flatness deviations increase with the growth of the part rigidity. In the subsequent grinding stages, the increase of part rigidity is accompanied by the favorable decrease of the flatness deviations. The compliance of low-rigid parts in the finishing stage of grinding should be reduced using additional technological devices.
\end{abstract}

\section{Introduction}

Rigidity is one of the most important factors in manufacture of machines and plays a dominant role in formation of the accuracy and the quality of part surfaces $[1,2]$. While manufacturing the compliant parts the following regularities are additionally taken into account: significant elastic and plastic deformations of the workpiece under influence of the cutting and inertia forces call the excessive static deflections; the low-rigidity parts are characterized by insufficient resistance to resist cutting forces, as a result of which the excessive forced oscillations (vibrations) are arisen; the workpiece distortion, generating the residual stress and decreasing their heat stability $[2,3]$.

Taking into account the above phenomena, there is a big complicacy while manufacturing the low-rigidity parts. In connection with the foregoing, the improvement of technological processes for processing the compliant parts is an important problem to increase the efficiency of manufacturing and the quality of engineering products [3].

Grinding process of hardened compliant parts was studied by Yang F., Zhang B. Khusainov A.Sh. and etc. There is not a consensus of opinion on the role of the rigidity of technological system (TS) while grinding the brittle materials, especially for provision of the dimension accuracy [4]. For example, Shore P. [5] considered that high rigidity has an important role for minimizing the defects of the ground surfaces. Jenkins H. and Kurfess T. [6] found that a high quality of the ground surfaces was received in a resonance when the dynamic rigidity of the TS is minimal. In paper [7], the experiments were carried out to determine influence of rigidity of the TS on the processing accuracy. It was found that increase of rigidity had no significant effect on the surface roundness and roughness. Zhang B. [8] confirmed that the residual stresses of the surface of the part from silicon nitride were decreased with increasing the TS rigidity. In papers $[8,4]$, the investigations were carried out to study influence of the TS rigidity on the forces, the cutting depth, the workpiece strength and the surface quality while grinding the ceramic parts. It has been established that the increase of the TS rigidity leads to increase the normal force and the cutting depth. There is a critical rigidity of the TS. The reduction of rigidity, which is lower than this value, can lead to a serious damage of the ground surface.

The problem of flat grinding of the thin-wall part was studied by Khusainova A.Sh. and Zubairova L.Kh. In [9] a technology of the defectless grinding was developed on the base of the decrease of the process heat-tensity. An investigation of forming the shape accuracy of thin plate during flat planetary face grinding was carried out in paper [10].

Unfortunately, until now there have been insufficient studies of processing the compliant parts, especially during grinding the flat parts. It is due to the complexity of simulation of their variable rigidity.

The purpose of this paper is to identify the influence of the rigidity on the formation of the form accuracy of the surfaces of the hardened steel parts using the statistical modeling the flatness deviations at difference stages of flat grinding.

*Corresponding author: nhatle007@gmail.com 


\section{Methodology of the experiment}

In this study, the constructional steel $30 \mathrm{KhGSA}\left(\sigma_{\text {UST }}=1080\right.$ $\mathrm{MPa}, \sigma_{0,2}=835 \mathrm{MPa}, \delta=10 \%$ ) was used to investigate. It was subjected to heat-treat regimes: hardening and abatement. This steel are used in aircraft industry to manufacture responsible high-loaded parts of the flying vehicles, operating under alternating loads. The full-scale experiments were carried out on a planogrinding machine of model $3 \mathrm{G} 71$. The applied liquid lubricant is $5 \%$ emulsion Akvol-6 (TU 0258-024-00148845-98), which is supplied by sprinkling on the part in volume of $7-101 / \mathrm{min}$. The objects of the study are specimens with sizes $B \times L \times H=40 \times 40 \times 50$ mm. Grinding was carried out along the plane $B \times L$. In this study a grinding wheel, which has the shape 01 and the size $250 \times 20 \times 76 \mathrm{~mm}$ and the characteristic 5NQ 46 I $6 \mathrm{~V} \mathrm{~S} 3$ (company Norton, the USA). An arrangement of variable compliance, having a ring-bridge structure, was used to regulate the rigidity. Its sketch is shown in Figure 1. An thick-walled fixed table from assembly-and-disassembly device (ADD) was fixed on this arrangement. Its deformation under the impact of the normal cutting force $P_{y}$ can be neglected. Thus, the frame of the arrangement is deformed in the direction of the machine table under the impact of the tangential force $P_{z}$ by the direction of the longitudinal feed $\mathrm{s}_{1}$ (Figure 2).

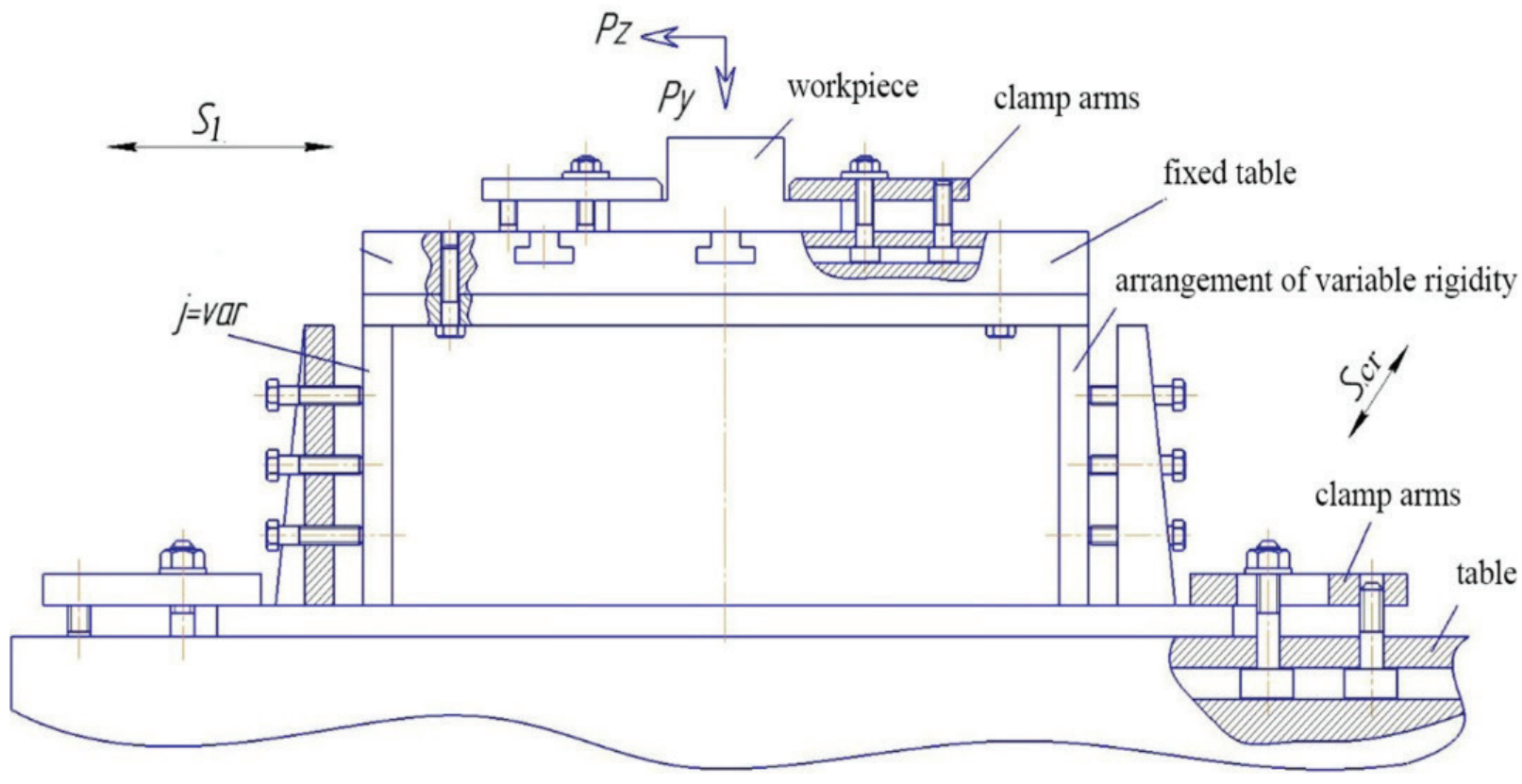

Fig. 1. Sketch of arrangement of variable rigidity.

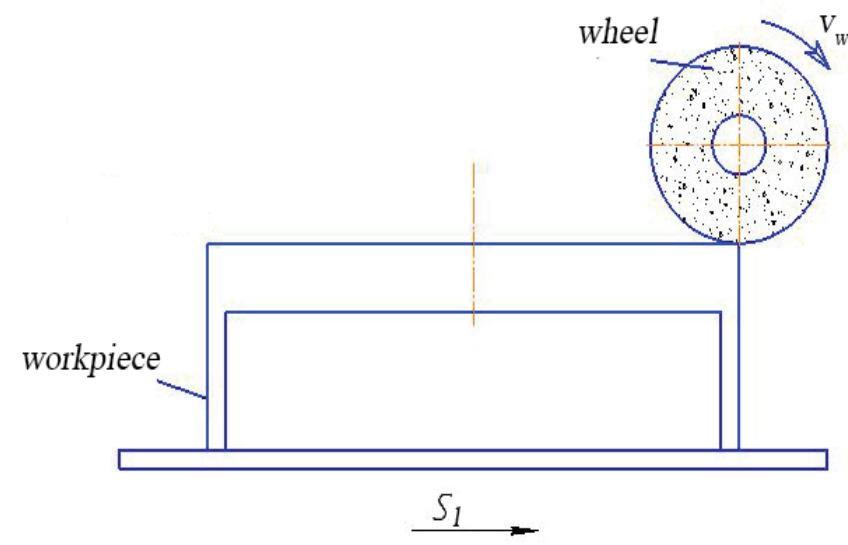

a)

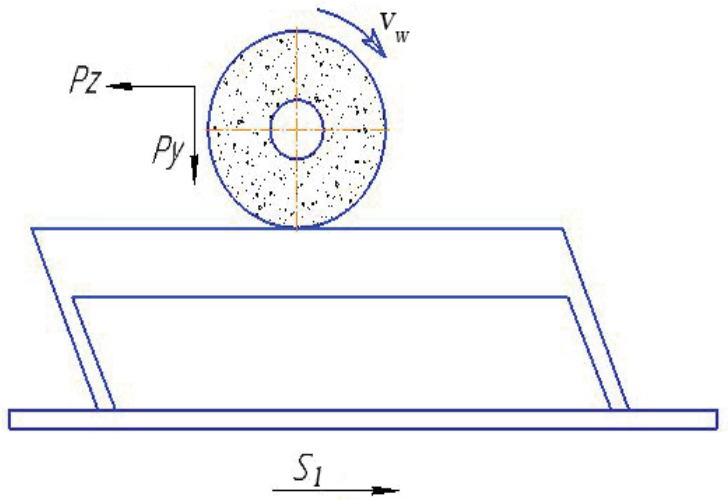

b)

Fig. 2. Scheme of grinding the compliant parts: a) cutting of the wheel into the part; b) grinding process. 
The variable rigidity of the arrangement and, therefore, of the part was provide by varying the height of the frame ribs and their pressing with bolts on a different distance from the setting base of the machine table

The deviation from the flatness of the ground surfaces were measured by a twisted-spring micrometer 2-IPM (TU 2-234-229-89). According to GOST 24642-81, they are represented by three indicators: $E F E_{\max }$ (main) and two additional ones - the arithmetic average $E F E_{a}$ and the quadratic average $E F E_{q}$.

The workpieces were ground using D-optimal design of experiment in multiple dispersion analysis (MDA). Its matrix was presented in paper [11] under the condition specified in Table 1.

Table 1. Variation intervals and levels of natural and normalized factors

\begin{tabular}{|c|c|c|c|c|}
\hline \multirow[b]{2}{*}{ Factors } & \multirow[b]{2}{*}{ Variation intervals } & \multicolumn{3}{|c|}{ Factor levels } \\
\hline & & $\begin{array}{l}\text { lower } \\
(-1.0)\end{array}$ & $\begin{array}{l}\text { base } \\
(0.0)\end{array}$ & $\begin{array}{l}\text { upper } \\
(+\mathbf{1 . 0})\end{array}$ \\
\hline$A-$ longitudinal feed $s_{l}, \mathrm{~m} / \mathrm{min}$ & 5 & 5.0 & 10 & 15 \\
\hline$B-$ cross feed $s_{\mathrm{c}}, \mathrm{mm} /$ double stroke & 4 & 2 & 6 & 10 \\
\hline$C$ - cutting depth $t, \mathrm{~mm}$ & 0.0075 & 0.005 & 0.0125 & 0.020 \\
\hline$D$ - operational allowance $z, \mathrm{~mm}$ & 0.1 & 0.1 & 0.2 & 0.3 \\
\hline$E-$ rigidity $j, \mathrm{H} / \mathrm{MM}$ & 5420 & 380 & 5800 & 11220 \\
\hline
\end{tabular}

Initially, the MDA models were constructed using the last square method. The received models were tested for the adequacy in relation of signal-to-noise, as well as for multicollinearity and emission. The expediency of transforming the original model using the maximum likelihood method was determined by the Cox-Box criterion. Implementation of this approach is accomplished using a well-known statistical software Design-Expert. The procedure of finding models was described in detail in paper [11].

\section{Research results and discussion}

Based on the research and modeling results, the following models of the form accuracy indicators are obtained in Eq. (1) - Eq. (6). They were finally carried out using the maximum likelihood method:

the normalized form

$\widehat{E F E}_{\text {max }}=\exp (2.02+0.025 \mathrm{~A}+0.12 \mathrm{~B}+0.11 \mathrm{C}-0.039 \mathrm{D}-0.086 \mathrm{E}+0.086 \mathrm{~A} \mathrm{E}-0.062 \mathrm{C} \mathrm{D}+$

$\left.+0.12 \mathrm{CE}+0.10 \mathrm{~A}^{2}-0.17 \mathrm{E}^{2}\right), \mu \mathrm{m}$;

$\widehat{E F E}_{a}=\left(1.98+3.054 \times 10^{-3} \mathrm{~A}+0.095 \mathrm{~B}+0.080 \mathrm{C}-0.025 \mathrm{D}-0.095 \mathrm{E}+0.070 \mathrm{~A} \mathrm{C}+0.10 \mathrm{AE}+\right.$

$+0.082 \mathrm{C} \mathrm{E}+0.079 \mathrm{D} \mathrm{E})^{2}, \mu \mathrm{m}$

$\widehat{E F E}_{q}=(2.12+0.028 \mathrm{~A}+0.11 \mathrm{~B}+0.10 \mathrm{C}-0.026 \mathrm{D}-0.100 \mathrm{E}+0.066 \mathrm{~A} \mathrm{C}+0.10 \mathrm{~A} \mathrm{E}-0.049 \mathrm{C} \mathrm{D}+$

the nature form

$\widehat{E F E}_{\max }=\exp \left(2.16848-0.095456 s_{\text {пр }}+0.030782 s_{\text {пा }}+14.56231 \mathrm{t}+0.65020 \mathrm{z}-1.58242 \times 10^{-5} \mathrm{j}+\right.$

$+3.15766 \times 10^{-6} s_{\text {пр }} \mathrm{j}-82.89884 \mathrm{t} \mathrm{z}+2.88452 \times 10^{-3} \mathrm{t} \mathrm{j}++4.10247 \times 10^{-3} s_{\text {пр }}^{2}$

$\left.-5.84124 \times 10^{-9} j^{2}\right), \mu \mathrm{m}$;

$\widehat{E F E}_{a}=\left(2.61753-0.044938 s_{\text {пр }}+0.023637 s_{\text {п }}-19.54310 \mathrm{t}-1.09861 \mathrm{z}-1.10214 \times 10^{-4} \mathrm{j}+1.85587 s_{\text {пр }} \mathrm{t}+\right.$

$\left.+3.85356 \times 10^{-6} s_{\text {пр }} \mathrm{j}+2.00757 \times 10^{-3} \mathrm{t} \mathrm{j}+1.45549 \times 10^{-4} \mathrm{z} \mathrm{j}\right)^{2}, \mu \mathrm{m}$;

$\widehat{E F E}_{q}=\left(2.77559-0.12765 s_{\text {пр }}+0.026805 s_{\text {п }}-4.45867 \mathrm{t}-0.088511 \mathrm{z}-5.96140 \times 10^{-5} \mathrm{j}+1.75498 s_{\text {пр }} \mathrm{t}+\right.$

$+3.84351 \times 10^{-6} s_{\text {пр }} \mathrm{j}-65.98721 \mathrm{t} \mathrm{z}+2.38119 \times 10^{-3} \mathrm{t} \mathrm{j}+1.12586 \times 10^{-4} \mathrm{z} \mathrm{j}+4.45203 \times 10^{-3} s_{\text {пр }}^{2}-$

$\left.-4.27128 \times 10^{-9} j^{2}\right)^{2}, \mu \mathrm{m}$.

The obtained models Eq. (1) - Eq. (6) allow to estimate the influence of each technological factor on the form accuracy of the ground parts. Models Eq. (1) - Eq. (3) additionally allow to predict the intensity and direction of the response variation using the coefficient and sign of mail factors. At that longitudinal feed (A), cross feed (B) and cutting depth $(\mathrm{C})$ cause the growth of all researched accuracy indicators, and operating allowance (D) and

rigidity $(E)$ - their decrease. It can be seen from Eq. (1) Eq. (3) that to reduce the flatness deviations it shout be decrease cross feed and cutting depth and increase the part rigidity. As will be shown below, the paired interactions of factors and the quadratic effects introduce additional influences on the studying phenomena.

Fig. 3 shows the influence of part rigidity on indicators of flatness deviations on different grinding stages. At that 
the roughing, semi-finishing and finishing stages of grinding are carried out consecutively in the following modes: $\mathrm{A}=\mathrm{B}=\mathrm{C}=\mathrm{D}=+1,0, \mathrm{~A}=\mathrm{B}=\mathrm{C}=\mathrm{D}=0,0, \mathrm{~A}=\mathrm{B}=\mathrm{C}=\mathrm{D}=$ 1,0 (Table 1).

Fig. 3 shows that the part rigidity significantly influences on formation of the surface shape accuracy.
When the part rigidity is varied from $380 \mathrm{~N} / \mathrm{mm}$ to 11220 $\mathrm{N} / \mathrm{mm}$ the parameters of the flatness deviations are changed to 1.4 times on the rough, to 1.3 times on semi-finishing and 2.2 times on finishing grinding.

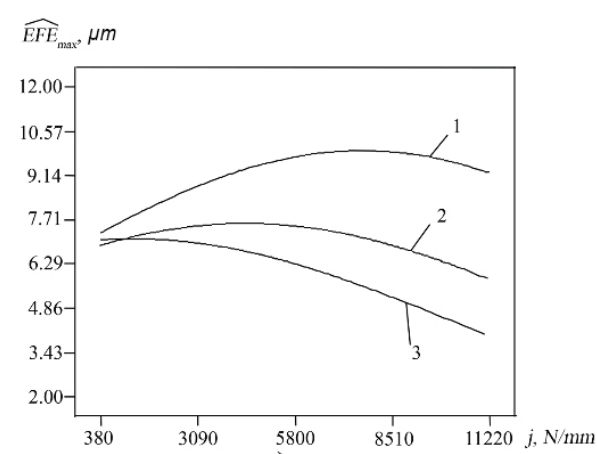

a)

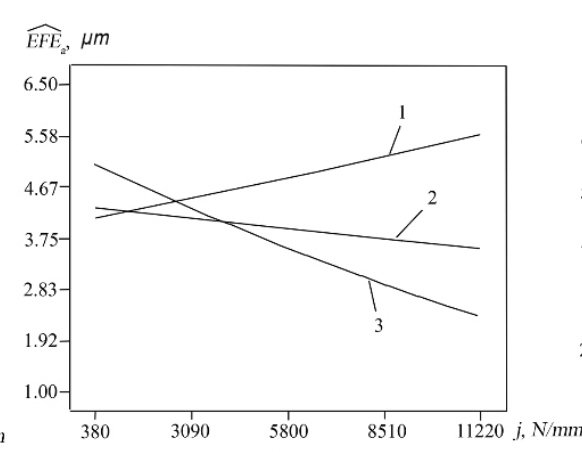

b)

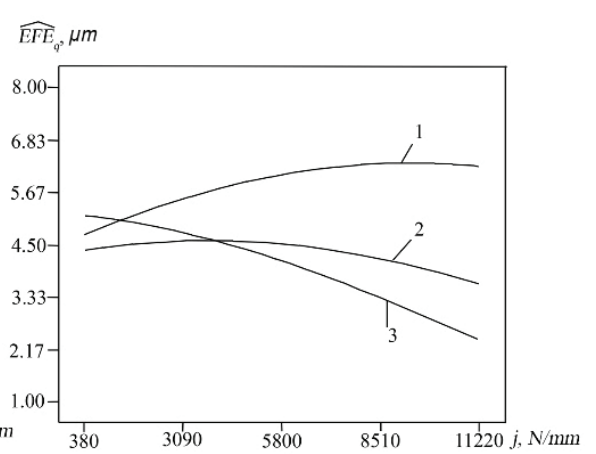

Fig. 3. Influence of the part rigidity on the indicators of the flatness deviations: $\mathrm{a}-\widehat{E F E}_{\text {max }} ; \mathrm{b}-\widehat{E F E}_{a}, \mathrm{c}-\widehat{E F E}_{q}$, during stage grinding: 1 - rough; 2 - semi-finishing; 3 - finishing

In rough grinding stage (line 1), with increasing the part rigidity, the value of $\widehat{E F E}_{\text {max }}$ increases to maximum at $j=$ $7629 \mathrm{~N} / \mathrm{mm}$, and with its further growth - decreases (line 1, Fig. 3a). A similar regularity was noted for the parameter $\widehat{E F E}_{q}$ (line 1, Fig. 3c) with displacement of extremum to the point $j=9980 \mathrm{~N} / \mathrm{mm}$. For the parameter $\widehat{E F E}_{a}$ the increase of rigidity leads to a monotonic increase in its value (line 1 , Fig. 3b).

In semi-finish grinding stage, the observed regularities are preserved for $\widehat{E F E}_{\text {max }}$ and $\widehat{E F E}_{q}$ (line 2, Fig. 3,a,c). The greatest extremums of these lines $\widehat{E F E}_{\text {max }, q}=f(j)$ correspond to smaller rigidity of the parts. For parameter $\widehat{E F E}_{a}$, the increase of rigidity leads to a monotonic decrease in its value (line 2, Fig. 3b).

In finish grinding stage, the increase of part rigidity is accompanied by a decrease of all parameters of flatness deviations from the maximum to the minimum (line 3 , Fig. 3).

The noted regularity of the influence of rigidity on the parameters of the form accuracy of ground part surface at different stages can be explained as follows. The rough grinding was carried out with the greatest intensive technological parameters that leads to an increase of the wheel impact when it cuts into the rigid workpiece and an decrease it form accuracy. Low-rigid parts $j=380 \mathrm{~N} / \mathrm{mm}$ have great damping properties, as materials with great internal friction. They quench this impact when cutting into the workpiece. It leads to increase the form accuracy while grinding the low-rigid parts at the rough stage. The obtained result in the rough grinding about the increase of the form accuracy of the low-rigid parts up to 1.4 time is a scientific novelty, because it is always recommended to increase its rigidity in the normative documents.
The semi-finish and especially finish grinding were carried out with a less intensive stock removal. By this reason, the wheel impact into the workpiece is decreased in comparison with the rough stage. The plastic deformations and vibrations, which are the feature of grinding low-rigid parts, increase their influence on the forming the flatness deviations. It is known that they were greater during processing the lower rigid parts than during grinding parts with high rigidity. It explains the decrease of parameters of flatness deviations while increasing the part rigidity.

The obtained results allowed to make the recommendations for increasing the form accuracy in finish grinding the low-rigid parts. One solution to solve this problem is the use of fixture devices as vacuum fixtures, adaptive fixtures using low melting temperature alloys or automated fixtures. Another alternative solution is the use of actuators that compensate online the deformation and vibration of the part. Finally, another solution is the study of the process by means of optimization of the cutting conditions and the study of the dynamic response of the workpiece during the machining. This is a predictive knowledge-based solution, flexible and universal, as it can be applied to every part, and far less expensive than others $[11,13,14]$.

\section{Conslusions}

1. It was established that the rigidity of hardened steel parts had a significant influence on forming the shape accuracy of the ground surface.

2. It is revealed that in the rough grinding stage, the increase of the part rigidity leads to an increase of parameters of flatness deviations, and in the finishing stage - to a decrease of them. 
3. For provision of the form accuracy of low-rigid parts during finishing stage of grinding, the additional measures should be used to increase their rigidity.

The authors gratefully acknowledge the support by Irkutsk National Research Technical University under Grant No. 02F/2016 and by The Ministry of Education and Science of the Russian Federation under Grant No. 9.6484.2017/BCh.

\section{References}

1. M. Ebrahimi, R. Whalley, Computers \& Industrial Engineering, 38 (2000)

2. A. Świć, W. Taranenko, Eksploatacja i Niezawodnosc - Maintenance and Reliability, 14, 3 (2012)

3. O.I. Drachev, Control of technological heredity of parts with low rigidity (Research-and-production cooperative "Association of Scientific Engineering Commercial Structures", 2011)

4. F. Yang, et al., Journal of Manufacturing Science and Engineering, 123 (2001)

5. P. Shore, British Ceramic Proceedings, 46 (1990)

6. H. Jenkins, T. Kurfess, Journal of Vibration and Control, 3 (1997)

7. B. Colding, Machinery, 76, 7 (1970)

8. B. Zhang, Annals of the CIRP, 50, 1 (2001)

9. A.Sh. Khusainov, Increase in the efficiency of grinding operations of blanks of thin-walled parts by reducing the heat stress of the processing process (Ulyanovsk State Tech. Un-t, Ulyanovsk, 1996)
10. L.Kh. Zubairova, Technological support of the required accuracy of the shape of thin-walled parts with flat face planetary grinding (Perm. Nat. reach. Polit. Un-t, Perm, 2014)

11. Nguyen Van Le, Providing the required quality of surfaces during flat grinding of hardened steel parts with various rigidity (IRNITU, Irkutsk, 2017)

12. Ya.I. Soler, Nguyen Van Le, D.Yu Kazimirov, Proceedings of higher educational institutions. Mechanical engineering, 4, 673 (2016)

13. S. Ratchev, S. Liu, A. A. Becker, Journal of Materials Processing Technology, 162-163 (2005)

14. F.J. Campa, L.N. de Lacalle Lopez, G. Urbikain, D. Ruiz, Proceedings of the 2008 International Manufacturing Science and Engineering Conference, (2008) 